\title{
Cultura comunicacional atual: relações comunicação/consumo
}

Maria Inês Carlos Magno e Fernanda Elouise Budag

\section{Resenha}

BACCEGA, Maria Aparecida (org.). Comunicação e

culturas do consumo. São Paulo: Atlas, 2009.

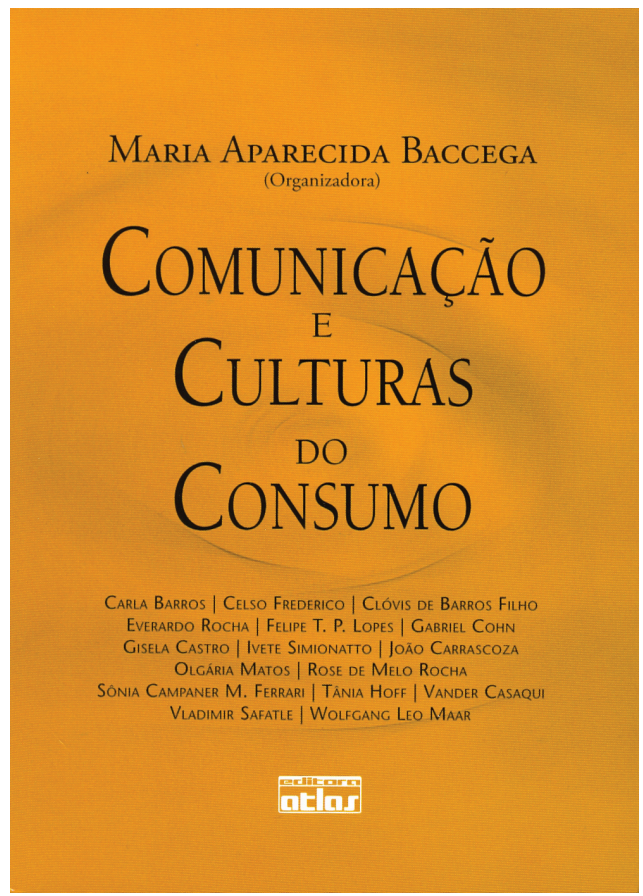

Maria Inês Carlos Magno | unsigster@gmail.com

Doutora em Ciências da Comunicação pela Universidade de São Paulo - USP. Professora do Programa de Mestrado em Comunicação da Universidade Anhembi Morumbi - UAM.

\section{Fernanda Elouise Budag | fbudag@espm.br}

Mestre em Comunicação e Práticas de Consumo pela Escola Superior de Propaganda e Marketing - ESPM/SP. Pesquisadora Jr. do mesmo Programa.
A superficialidade, o desenraizamento, a velocidade no lugar da duração, nas palavras da organizadora, são algumas das características de nossa contemporaneidade que colocam em operação e garantem a permanência do consumo no centro de nossas práticas socioculturais, engendradas pela comunicaçãomídia. Comunicação e culturas do consumo emerge, pois, como obra fundamental na tentativa de entendimento e esclarecimento do espírito de nosso tempo. 0 livro promove uma reflexão acadêmica do consumo, desvelando seu pertencimento no campo da comunicação. Essa arena, da relação comunicação/consumo, é justamente 0 território de lutas e debates do Programa de Mestrado em Comunicação e Práticas de Consumo da Escola Superior de Propaganda e Marketing - ESPM/SP, qual a organizadora faz parte. Essa instituição também promove 0 Simpósio Nacional Comunicação e Práticas de Consumo, o qual, por sua vez, em sua quinta edição (2007), gerou os textos deste volume.

Revisitando grandes pensadores, os autores dos textos que compõem a obra fazem ricas leituras 
e trazem luz aos estudos das relações entre comunicação e consumo. A organizadora divide e distribui os textos em três grandes blocos bem definidos, mas que também se complementam. Na primeira parte -Reflexões de Benjamin, Habermas, Horkheimer e Adorno: modernidade, o novo sensorium -, os quatro autores retornam aos tempos em que a sociedade do consumo estava ainda no seu início, ainda na construção dos contornos que iria ganhar, para explorar o que agora já está sedimentado e - por que não - naturalizado. Olgaria Matos passeia por Paris e pelos pensamentos de Walter Benjamin para procurar entender a sociedade do consumo que estava emergindo. A mesma cidade e 0 mesmo autor também são trazidos à tona por Sônia Campaner M. Ferrari para, a partir da fantasmagoria, trabalhar a questão da fascinação dos bens sobre os consumidores. Partindo de Habermas, Wolfgang Leo Maar discute as mudanças na esfera pública com a nova formação social que surge no século XX: a sociedade de massa. Continuando na mesma linha e finalizando este bloco, Gabriel Cohn retoma o sexagenário conceito de indústria cultural, revelando sua complexidade.

A segunda parte-Marx, Gramsci, Bourdieu, política, tecnologias: relações com o consumo -, da mesma forma, traz as contribuições de outros clássicos. 0 consumo, a partir de Marx; as formas de produção e demais esferas que as envolvem, a partir de Gramsci; e o gosto, a partir de Bourdieu são os principais. Celso Frederico é quem traz Marx para o centro da discussão sobre 0 consumo: enfatiza a inter-relação entre produção, circulação e consumo, bem como a dominância desta última fase no interior desse processo. Já Ivete Simionatto percorre os escritos de Gramsci e constata que parece estar no movimento dialético entre estrutura e superestrutura a contribuição maior deste teórico italiano para se pensar as manifestações da comunicação e do consumo na sociedade capitalista. Continuando, consumo remete a gostos, e é dessa temática que tratam Clóvis de Barros Filho e Felipe Tavares Paes Lopes em A dominação pelo gosto: 0 consumo na sociologia de Bourdieu. Segundo Bourdieu, o gosto é socialmente construído e a, por ele denominada, "ideologia do gosto natural" opera naturalizando diferenças que são sociais. Na sequência, os olhares de Rose de Melo Rocha e Gisela Castro iluminam os pensamentos sobre a comunicação e a mídia nas suas múltiplas interfaces com as práticas de consumo. Castro centrou sua discussão na articulação entre mídia e consumo no mercado globalizado, explorando aí os padrões midiáticos que atuam como moduladores identitários. Já Rocha assume uma leitura essencialmente política desta relação comunicação-consumo, reconhecendo de antemão o alastramento social da mídia e 0 consumo como conjunto de processos socioculturais complexos.

Marcas, grifes, símbolos e estilos de vida, que fazem inevitavelmente parte do cotidiano de consumidores/cidadãos de pequenas cidades a 
grandes metrópoles, são "vendidos" em Consumo e publicidade, a terceira parte do livro. A publicidade é uma esfera fulcral nas culturas do consumo por ser a categoria de comunicação que coloca explicitamente em circulação as mensagens que objetivam diretamente o consumo, promovendo a manutenção do sistema. João Carrascoza, objetivando tratar da publicidade e suas interações com 0 consumo, detém-se em representativas estratégias retóricas de anúncios, que, afinal, em sua essência, pretendem inserir o sujeito na sociedade do consumo. Em Entre mundos distintos: notas sobre comunicação e consumo em um grupo social, Everardo Rocha e Carla Barros percorrem caminhos para vencer o desafio de construir um conhecimento mais amplo do complexo universo do consumo, entendido como experiência de cultura. E no centro desta cultura do consumo parece estar o corpo. Daí a problematização que realiza Vladimir Safatle da atual transformação do corpo em palco fundamental de manifestação de aspirações políticas. Igualmente, Tânia Hoff, em estudo analítico, constata que as representações de corpo na publicidade brasileira permitem perceber ideologias, preconceitos e aspirações de cada época numa trajetória histórica. Ainda dentro da lógica do consumo, 0 mundo do trabalho é explorado por Vander Casaqui a partir das diretrizes de Marx e Engels, numa tentativa de identificar suas transformações. As mudanças sinalizam que 0 trabalho parece passar de local de tensões para local de conformação harmônica ao mundo dos produtos.

Finalizando a obra, o leitor percebe que se trata apenas de um início. Um início dos estudos acadêmicos do consumo que, sem estereótipos, não foge das dimensões polêmicas e complexas do tema. 0 livro deixa claro que, nas grandes dimensões da cultura comunicacional atual, a comunicação pressupõe obrigatoriamente seu outro lado, o consumo, as práticas de consumo material e simbólico. 


\section{Expediente}

A revista E-Compós é a publicação científica em formato eletrônico da Associação Nacional dos Programas de Pós-Graduação em Comunicação (Compós). Lançada em 2004, tem como principal finalidade difundir a produção acadêmica de pesquisadores da área de Comunicação, inseridos em instituições do Brasil e do exterior.
E-COMPÓS I www.e-compos.org.br I E-ISSN 1808-2599

Revista da Associação Nacional dos Programas de Pós-Graduação em Comunicação. Brasília, v.12, n.2, maio/ago. 2009

A identificação das edições, a partir de 2008 passa a ser volume anual com três números.

\section{CONSELHO EDITORIAL}

\section{Afonso Albuquerque}

Universidade Federal Fluminense, Brasil

Alberto Carlos Augusto Klein

Universidade Estadual de Londrina, Brasi

Alex Fernando Teixeira Primo

Universidade Federal do Rio Grande do Sul, Brasi

\section{Alfredo Vizeu}

Universidade Federal de Pernambuco, Brasil

Ana Carolina Damboriarena Escosteguy

Pontifícia Universidade Católica do Rio Grande do Sul, Bras

Ana Silvia Lopes Davi Médola

Universidade Estadual Paulista, Brasil

André Luiz Martins Lemos

Universidade Federal da Bahia, Brasil

Ângela Freire Prysthon

Universidade Federal de Pernambuco, Brasil

Antônio Fausto Neto

Universidade do Vale do Rio dos Sinos, Brasil

Antonio Carlos Hohlfeldt

Pontifícia Universidade Católica do Rio Grande do Sul, Brasil

Arlindo Ribeiro Machado

Universidade de São Paulo, Brasil

César Geraldo Guimarães

Universidade Federal de Minas Gerais, Brasil

Cristiane Freitas Gutfreind

Pontifícia Universidade Católica do Rio Grande do Sul, Brasil

Denilson Lopes

Universidade Federal do Rio de Janeiro, Brasil

Eduardo Peñuela Cañizal

Universidade Paulista, Brasi

Erick Felinto de Oliveira

Universidade do Estado do Rio de Janeiro, Brasil

Francisco Menezes Martins

Universidade Tuiuti do Paraná, Brasil

Gelson Santana

Universidade Anhembi/Morumbi, Brasi

Hector Ospina

Universidad de Manizales, Colômbia

leda Tucherman

Universidade Federal do Rio de Janeiro, Brasil

Itania Maria Mota Gomes

Universidade Federal da Bahia, Brasil

Janice Caiafa

Universidade Federal do Rio de Janeiro, Brasil

Jeder Silveira Janotti Junior

Universidade Federal da Bahia, Brasil
João Freire Filho

Universidade Federal do Rio de Janeiro, Brasil

John DH Downing

University of Texas at Austin, Estados Unidos

José Luiz Aidar Prado

Pontifícia Universidade Católica de São Paulo, Brasil

José Luiz Warren Jardim Gomes Braga

Universidade do Vale do Rio dos Sinos, Brasil

Juremir Machado da Silva

Pontifícia Universidade Católica do Rio Grande do Sul, Brasil

Lorraine Leu

University of Bristol, Grã-Bretanha

Luiz Claudio Martino

Universidade de Brasília, Brasil

Maria Immacolata Vassallo de Lopes

Universidade de São Paulo, Brasil

Maria Lucia Santaella

Pontifícia Universidade Católica de São Paulo, Brasil

Mauro Pereira Porto

Tulane University, Estados Unidos

Muniz Sodre de Araujo Cabral

Universidade Federal do Rio de Janeiro, Brasil

Nilda Aparecida Jacks

Universidade Federal do Rio Grande do Sul, Brasil

Paulo Roberto Gibaldi Vaz

Universidade Federal do Rio de Janeiro, Brasil

Renato Cordeiro Gomes

Pontifícia Universidade Católica do Rio de Janeiro, Brasil

Ronaldo George Hela

Universidade do Estado do Rio de Janeiro, Brasil

Rosana de Lima Soares

Universidade de São Paulo, Brasil

Rossana Reguillo

Instituto Tecnológico y de Estudios Superiores do Occidente, México

Rousiley Celi Moreira Maia

Universidade Federal de Minas Gerais, Brasil

Sebastião Carlos de Morais Squirra

Universidade Metodista de São Paulo, Brasil

Simone Maria Andrade Pereira de Sá

Universidade Federal Fluminense, Brasi

Suzete Venturelli

Universidade de Brasília, Brasil

Valério Cruz Brittos

Universidade do Vale do Rio dos Sinos, Brasil

Veneza Mayora Ronsini

Universidade Federal de Santa Maria, Brasil

Vera Regina Veiga França

Universidade Federal de Minas Gerais, Brasil
COMISSÃO EDITORIAL

Ana Gruszynski I Universidade Federal do Rio Grande do Sul, Brasil Felipe da Costa Trotta I Universidade Federal de Pernambuco Rose Melo Rocha I Escola Superior de Propaganda e Marketing, Brasil

\section{CONSULTORES AD HOC}

Aníbal Francisco Alves Bragança I Universidade Federal Fluminense Benjamim Picado I Universidade Federal da Bahia

Carlos Eduardo Franciscato I Universidade Federal de Sergipe

Christa Liselote Berger I Universidade Vale do Rio dos Sinos

Gisela Castro I Escola Superior de Propaganda e Marketing Luciana Pellin Mielniczuk I Universidade Federal de Santa Maria Marcia Benetti I Universidade Federal do Rio Grande do Sul

Paulo Cunha Carneiro Filho I Universidade Federal de Pernambuco

Raquel Recuero I Universidade Católica de Pelotas

REVISÃO DE TEXTO E TRADUÇÃO I Everton Cardoso

EDITORAÇÃO ELETRÔNICA I Raquel Castedo
COMPÓS I www.compos.org.br

Associação Nacional dos Programas de Pós-Graduação em Comunicação

Presidente

Itania Maria Mota Gomes

Universidade Federal da Bahia, Brasil

itania@ufba.br

Vice-presidente

Julio Pinto

Pontifícia Universidade Católica de Minas Gerais, Brasil

juliopinto@pucminas.br

Secretária-Geral

Ana Carolina Escosteguy

Pontifícia Universidade Católica do Rio Grande do Sul, Brasil

carolad@pucrs.br 